\title{
Детерминанты метода платежа в сделках слияний и поглощений на развивающихся рынках капитала
}

\author{
Григорьева С.А. ${ }^{17}$, Фоменко Н.В. ${ }^{18}$
}

Влияние сделок слияний и поглощений на стоимость компаний продолжает активно обсуждаться в финансово-экономической литературе. Одним из факторов, определяющих эффективность сделок $M \& A$, который заслуживает пристального внимания и изучения, является способ оплаты сделки. Основываясь на выборке, включающей 825 сделок М\&А в странах БРИКС, совершенных в период с 1999 по 2009 года, мы доказываем, что при выборе метода платежа в сделках слияний и поглощений имеют значение следующие факторы: доступность финансовых ресурсов, относительный и абсолютный размер сделки, доля институциональных инвесторов в акционерном капитале компании-покупателя, динамика отношения рыночной стоимости компании-покупателя кее балансовой стоимости, размер приобретаемой и имеющейся доли компании-цели.

\section{JEL: $G 34$}

Ключевые слова: слияния и поглощееня, метод платежа, развивающиеся рынки капитала

Особого внимания при осуществлении любой сделки М\&A требует вопрос способа оплаты слияний и поглощений. Правильный выбор финансирования и структуры оплаты сделок M\&A ведет к снижению затрат компании на капитал, диверсификации рисков, связанных с заключенной сделкой, и росту благосостояния акционеров компаниипокупателя. Понимание детерминант метода платежа способствует ориентации менеджмента и совета директоров компаний на принятие обоснованных решений об использовании того или иного способа финансирования и оплаты сделки M\&A.

В отличие от существующих эмпирических работ, исследующих метод платежа в сделках M\&A на развитых рынках капитала, в данной статье изучаются детерминанты способа оплаты слияний и поглощений на развивающихся рынках. В условиях данных рынков менеджмент компаний-покупателей может руководствоваться другими мотивами при выборе метода платежа, поскольку рынки долгового и акционерного капитала развиты сравнительно меньше, а глубина асимметрии информации значительно выше.

Статья структурирована следующим образом. В первую очередь мы приводим обзор теорий выбора метода платежа в сделках слияний и поглощений и обсуждаем результаты основных исследований, выполненных на данных компаний с развитых рынков капитала. Далее мы формулируем гипотезы для тестирования на развивающихся рынках капитала, представляем описание выборки и модели собственного исследования. В конце приводим основные результаты и обсуждаем возможные направления для дальнейшего научного поиска.

\section{Обзор теорий выбора метода платежа в сделках M\&A}

При слияниях и поглощениях могут использоваться различные способы оплаты сделок: денежные средства, акции компании-покупателя и комбинация денежных средств и акций.

С точки зрения акционеров компании-цели, преимуществом денежных средств является их ликвидность, а также тот факт, что сумма полученных в итоге средств не

\footnotetext{
${ }^{17}$ Канд. эконом. наук, доцент кафедры экономики и финансов фирмы НИУ ВШЭ.

${ }^{18}$ Выпускник бакалавриата по специальности «Экономика и финансы фирмы» НИУ ВШЭ.
} 
изменится в результате падения стоимости акций компании-покупателя в будущем. Негативным аспектом является то, что в случае использования денежных средств в качестве способа оплаты, акционерам покупаемой компании необходимо сразу заплатить налог на прирост капитала (capital gain tax). В случае же использования акций выплата налога отсрочена и должна быть произведена после продажи соответствующих акций, что является определенным преимуществом.

С точки зрения акционеров и менеджеров компании-покупателя, использование собственного капитала привлекательно, поскольку доля существующих акционеров не размывается. Однако с другой стороны, использование денежных средств приводит к увеличению долговой нагрузки на компанию-покупателя и/или сокращает уровень ее ликвидности. Имеется также ряд других мотивов, которыми могут руководствоваться стороны сделки M\&A при выборе метода платежа (Grinblatt-Titman, 2002; Martynova, Renneboog, 2011; Аглиарди, Лукъянова, 2011).

Существующие эмпирические работы, посвященные выявлению детерминант способа оплаты сделок M\&A, в большинстве своем основаны на рассмотрении слияний и поглощений на развитых рынках капитала. В таблице 1 суммированы результаты наиболее значимых исследований, изучающих факторы, влияющие на выбор метода платежа.

Таблица 1

Обобщение результатов исследований детерминант метода платежа на развитых рынках капитала

\begin{tabular}{|l|c|c|c|c|c|}
\hline \multicolumn{1}{|c|}{ Авторы } & Год & Период & $\begin{array}{c}\text { Рассмотренные } \\
\text { страны }\end{array}$ & $\begin{array}{c}\text { Кол-во } \\
\text { сделок }\end{array}$ & Прим. \\
\hline Carleton & 1984 & $1976-1977$ & США & 45 & - \\
\hline Hansen & 1987 & $1976-1978$ & США & 105 & - \\
\hline Travlos & 1987 & $1972-1981$ & США & 167 & - \\
\hline Amihud, Lev, Travlos & 1990 & $1981-1983$ & США & 209 & - \\
\hline Cornett, De & 1991 & $1982-1986$ & США & 132 & Банки \\
\hline Song, Walkling & 1993 & $1977-1986$ & США & 306 & - \\
\hline Martin & 1996 & $1979-1988$ & США & 846 & - \\
\hline Grullon, Michaely, Swary & 1997 & $1981-1990$ & США & 146 & Банки \\
\hline Ghosh, Ruland & 1998 & $1981-1988$ & США & 212 & - \\
\hline Zhang & 2001 & $1990-1999$ & Великобритания & 103 & - \\
\hline Faccio, Masulis & 2005 & $1997-2000$ & Страны Европы & 3667 & - \\
\hline Di Giuli & 2008 & $1984-2000$ & США & 1462 & - \\
\hline
\end{tabular}

Легко заметить, что исследователи в основном использовали данные о сделках в США и Европе. Очевидно, определяющим фактором в данном случае является доступность информации о сделках на развитых рынках, а также тот факт, что на данные регионы приходится основной объем сделок М\&A.

Для понимания того, что определяет выбор способа оплаты сделок слияний и поглощений, рассмотрим основные теории выбора метода платежа.

\section{Теория доступности финансовых ресурсов}

Согласно данной теории, компания-покупатель зачастую ограничена в возможности использования денежных средств в качестве метода платежа вследствие их недостаточности. Для финансирования сделок слияний и поглощений, оплачиваемых денежными средствами, в большинстве случаев привлекается долговое финансирование, поэтому второй причиной, повышающей вероятность использования акций, является трудность или нежелание увеличения долговой нагрузки компании-покупателя.

Теоретически, если у компании имеется большой запас денежных средств по отношению к стоимости ее активов, она может иметь большую свободу в использовании 
денежных средств в качестве способа оплаты. Размер компании-покупателя также может иметь значение, поскольку крупные диверсифицированные компании имеют больший доступ к рынкам заемного капитала.

В ходе эмпирического тестирования данной теории были получены различные результаты. В работе Факио и др. (Faccio et al., 2004) показано, что размер активов компании-покупателя и ее коэффициент долговой нагрузки являются значимыми (на 1\%-ном уровне значимости) факторами при выборе метода платежа, а также что специальный доступ к банковскому финансированию повышают вероятность выбора денежных средств в качестве способа оплаты в сделках M\&A.

В ряде других работ, например в работе Мартина (Martin, 1996), было обнаружено, что коэффициент долговой нагрузки и отношение денежных средств к размеру сделки незначимо влияют на метод платежа, а отношение чистого денежного потока к размеру сделки имеет неустойчивый знак.

\section{Теория асимметрии информации}

Данная теория была предложена в работе Майерса и Малуфа (Myers, Majluf, 1984) и основывается на предпосылке о наличии асимметрии информации между менеджментом компании-покупателя и остальными участниками рынка. В данных условиях менеджмент компании-покупателя может использовать информационную асимметрию при выборе метода платежа. Если менеджеры компании считают, что ее акции недооценены, то это повышает их стимулы к использованию денежных средств в качестве способа оплаты. В противном случае, если акции компании-покупателя переоценены, финансирование сделки с помощью дополнительной эмиссии акций может быть более предпочтительным. Данный эффект был также наглядно продемонстрирован в исследованиях других авторов (Dong et al., 2006; Rhodes-Kropf et al., 2005; Di Giuli, 2008). В качестве объясняющих переменных в данных работах обычно используются показатели Q Тобина, отношения рыночной стоимости активов компании к их балансовой стоимости и другие подобные переменные.

Однако асимметрия информация может воздействовать и с другой стороны. Неполнота информации в отношении стоимости компании-цели может приводить к использованию акций в качестве метода платежа. После официального объявления о предстоящей сделке участники рынка могут посчитать, что уплаченная за компанию-цель цена слишком высока. Это приведет к снижению цены акций компании-покупателя, что в итоге уменьшит и стоимость акций, полученных акционерами покупаемой компании.

В исследовании Хансена (Hansen, 1987) построена теоретическая модель, показывающая, что компания-покупатель может использовать акции для распределения риска переоценки компании-цели на ее акционеров. Данная модель была протестирована на выборке сделок, имевших место в США, которые подтвердили теоретические выводы исследователя.

\section{Теория инвестиционных возможностей}

С точки зрения данной теории при выборе метода платежа менеджмент компаниипокупателя руководствуется наличием у компании других перспективных инвестиционных возможностей. При условии существования таковых компания-покупатель будет более склонна к использованию акций при оплате сделок, что позволит сохранить денежные средства / избежать увеличения долговой нагрузки в результате совершения текущей сделки (Mayers, 1977) и сохранить возможность привлечения средств на долговых рынках.

Примерами работ, в которых была протестирована и подтверждена данная теория, могут быть исследования Мартина и Донга и др. (Martin, 1996; Dong et al., 1996). Однако тестирование описываемой теории на эмпирических данных достаточно затруднительно, поскольку в качестве объясняющих переменных в данном случае зачастую используются переменные, схожие с применением при тестировании теории асимметрии информации (отношение рыночной стоимости активов (собственного капитала) компании к их 
балансовой стоимости, Q Тобина). Считается, что у компаний с наличием выгодных инвестиционных возможностей в будущем данные показатели будут выше.

Попытка разделить данные эффекты была предпринята в работе Ди Гиули (Di Giuli, 2008). В качестве прокси-переменной для будущих инвестиционных возможностей были использованы капитальные затраты компании-покупателя за четыре года после совершения сделки, а для оценки переоцененности акций компании-покупателя использовалось отношение рыночной стоимости объединенной компании к ее балансовой стоимости. Использование данных о фактических затратах оправданно, поскольку они значительно коррелируют с ожидаемыми в момент совершения сделки M\&A капитальными затратами, что продемонстрировано в работе Ламонта (Lamont, 2000). Результаты исследования Ди Гуили показали, что компании, оплачивающие сделки M\&A с помощью акций, имеют более высокий уровень инвестиционных вложений в последующие годы после сделки, нежели компании, использующие для оплаты денежные средства (Di Giuli, 2008).

\section{Теория значимости относительного размера сделки}

Данная теория утверждает, что в случае если размер приобретаемой компании значителен по сравнению с компанией-покупателем, вероятность использования акций в качестве средства платежа повышается. Данный эффект объясняется тем, что в случае приобретения большой компании требуется значительный объем денежных средств и/или существенное увеличение долговой нагрузки.

Ряд эмпирических исследований подтверждает данную теорию (Grullon, 1997; Zhang, 2001; Dong, 2006). Авторами работ было обнаружено, что чем больше относительный размер компании-цели по сравнению с компанией-покупателем, тем больше вероятность использования акций либо сочетания акций и денежных средств в качестве способа оплаты сделок M\&A.

Однако в ряде других исследований были получены противоположные выводы. Например, в исследовании Мартина (Martin, 1996) утверждается, что отношение размера сделки к капитализации компании-покупателя за 20 дней до официального объявления о сделке незначимо (на 5\%-ном уровне значимости) влияет на выбор метода платежа в сделках слияний и поглощений.

Схожие результаты были получены в работе Гоша и Руланда, где было предложено следующее объяснение: с одной стороны, сравнительно большой размер сделки побуждает менеджмент компании-покупателя использовать акции в качестве средства платежа, поскольку это приведет к сравнительно меньшему ухудшению финансового положения компании (увеличению долговой нагрузки). Однако с другой стороны, использование акций будет способствовать значительному «разводнению» доли существующих акционеров компании-покупателя. Данные эффекты уравновешивают друг друга, поэтому суммарное влияние относительного размера сделки незначимо. Кроме того, при увеличении относительного размера компании-цели пропорционально растут и риски того, что ее активы были переоценены, что в свою очередь усиливает желание менеджмента компаниипокупателя перенести часть рисков на владельцев покупаемой компании и увеличивает вероятность использования акций в качестве средства платежа. Таким образом, относительный размер сделки можно считать своего рода катализатором, который увеличивает эффект других факторов, влияющих на выбор способа оплаты сделок слияний и поглощений (Ghosh, Ruland, 1998).

\section{Теория внешнего мониторинга}

Институциональные инвесторы могут выступать в качестве внешних контролеров деятельности менеджмента, подобную роль могут выполнять также инвесторы, владеющие контрольным пакетом акций компании-покупателя. Во многих исследованиях показано, что в случае использования акций в качестве средства платежа благосостояние акционеров компании-покупателя в среднем увеличивается меньше, нежели чем при использовании 
денежных средств, что может побуждать внешних контролеров блокировать решения по использованию акций (Bruner, Asquith, 1990; Blackburn et al., 1997; Bruner, 2004). Таким образом, если институциональные инвесторы владеют значительной долей компаниипокупателя, вероятность использования акций в качестве способа оплаты сделок М\&А снижается.

Кроме того, при предпосылке об оппортунистическом поведении менеджмента компании-покупателя использование акций представляется сравнительно более доступным методом платежа при ограниченных финансовых возможностях компании-покупателя, что в свою очередь может привести к совершению неэффективных сделок слияний и поглощений.

Данная теория нашла эмпирическое подтверждение в работе Мартина (Martin, 1996). Автор показал, что имеется значимая негативная взаимосвязь между долей компании, которой владеют институциональные инвесторы, и вероятностью использования акций в качестве способа оплаты, однако наличие блокирующего внешнего акционера не оказывает влияния на выбор метода платежа.

\section{Теория структуры собственности}

Данная теория интересует исследователей на протяжении многих лет и заключается в изучении значимости такого фактора при определении способа оплаты M\&A, как структура собственности компаний-участников сделок. Финансирование слияний и поглощений за счет выпуска акций компанией-покупателем приводит к разводнению контролируемой доли компании существующими акционерами. В случае если менеджмент компании-покупателя владеет долей акционерного капитала, решение может быть принято в пользу использования денежных средств в качестве способа платежа, чтобы не допустить потери контроля над компанией. Данный эффект должен быть более ярко выражен, если у компании имеется мажоритарный акционер. Подобное явление было отмечено в исследовании Стулза, в котором была выявлена отрицательная зависимость между вероятностью использования акций в качестве средства платежа и размером акционерного пакета, принадлежащего менеджменту компании-покупателя (Stulz, 1988). Позднее схожие результаты были получены Амихуд и др. (Amihud et al., 1990), которые на выборке из 209 слияний и поглощений, имевших место в США, показали, что в случае использования денежных средств пятерка топ-менеджеров с наиболее высоким положением в иерархии компании владела в среднем 11\% компании-покупателя, в случае использования акций они владели лишь 7\% компании.

Результаты работы Мартина (Martin, 1996) показали, что отрицательная зависимость между долей акционерного капитала, находящейся под контролем менеджмента компаниипокупателя, и вероятностью использования акций в качестве средства платежа, является нелинейной. Данная зависимость значима, если менеджмент компании владеет от 5 до 25\% голосующих акций, но ослабевает, если доля менеджмента выходит за рамки рассматриваемого интервала. Автор интерпретирует полученный результат следующим образом: если доля менеджмента в собственности компании высока, «разводнение» контроля имеет незначительные негативные последствия; если доля менеджмента мала, то он в меньшей степени озабочен вопросами корпоративного контроля.

Данные эффекты были также подтверждены в работе Гоша и Руланда (Ghosh, Ruland, 1998), помимо этого авторы обнаружили, что высокая концентрация акций в руках менеджмента компании-цели приводит к более высокой вероятности финансирования сделки акциями. Данное явление объясняется в работе желанием акционеров компании-цели сохранить часть контроля над объединенной компанией. Кроме того, получение некоторого контроля объединенной компанией может способствовать сохранению менеджментом компании-цели занимаемых должностей. Несмотря на разнонаправленность результатов относительно влияния доли менеджмента на способ оплаты сделок M\&A со стороны компании-покупателя и компании-цели, авторы показали, что фактор структуры собственности покупаемой компании более значим при определении метода платежа. 


\section{Гипотезы для развивающихся рынков}

Принимая во внимание проведенные исследования и полученные зависимости на развитых рынках капитала, а также доступность информации о сделках M\&A на развивающихся рынках, мы считаем целесообразным тестирование следующих семи гипотез применительно к компаниям из развивающихся стран.

Гипотеза 1. Гипотеза доступности финансовых ресурсов: чем выше доступность финансовых ресурсов и возможность привлечения дополнительного долга для компаниипокупателя, тем выше вероятность использования денежных средств в качестве способа оплаты.

Согласно теории иерархии методов финансирования (pecking order theory) менеджеры предпочитают привлекать финансовые ресурсы в следующем порядке: внутренние источники финансирования, долговое финансирование, привлечение средств на рынках акционерного капитала (Myers, Majluf, 1984). Использование акций в качестве средства платежа является, исходя из логики данной теории, наименее предпочтительным вариантом, при условии, что первые два источника не исчерпаны. Эмпирические работы доказывают существование иерархии методов финансирования (Martynova, Renneboog, 2009).

Для проверки данной гипотезы обычно используются следующие финансовые показатели (Martin,1996; Di Giuli, 2008):

- отношение денежных средств и их эквивалентов к балансовой стоимости активов компании-покупателя либо к размеру сделки M\&A;

- отношение свободного денежного потока к балансовой стоимости активов компаниипокупателя;

- коэффициент долговой нагрузки компании-покупателя («financial leverage»).

Относительно последнего показателя существуют два способа его расчета: в первом используется значение коэффициента долговой нагрузки, во втором - значение коэффициента долговой нагрузки, скорректированное на среднее значение данного показателя по отрасли, в которой работает компания-покупатель.

Первый подход был использован, например, в исследовании Ди Гиули, при этом коэффициент при данной переменной оказался незначимым. Второй подход, применение которого более обосновано, был использован в работе Мартина, однако взаимосвязь между методом платежа и коэффициентом долговой нагрузки также не была выявлена (DI Giuli, 2007; Martin, 1996).

Гипотеза 2. Гипотеза инвестиционных возможностей: чем выше инвестиционные возможности компании-покупателя в будущем, тем выще вероятность использования акиий в качестве средства платежа.

Для тестирования данной гипотезы наиболее целесообразно использовать методологию, предложенную в работе Ди Гиули (Di Giuli, 2007). Как было показано выше, в данной работе в качестве переменной, отражающей наличие перспективных инвестиционных возможностей у компании-покупателя на момент объявление о сделке, использовался фактический уровень инвестиционных затрат на протяжении четырех лет после завершения сделки, нормированный на балансовую стоимость активов компании.

Необходимо отметить, что в отличие от закономерности, представленной в гипотезе 2 , может иметь место противоположный эффект. Сделки М\&A могут представляться менеджеру компании-покупателя как одна из форм капитальных затрат. В данном случае, с точки зрения менеджера компании, использование денежных средств в качестве способа оплаты может быть более оправданным, в особенности в случае сравнительно небольших по размеру сделок. Таким образом, размер инвестиционных затрат после завершения сделки может различным образом влиять на выбор метода платежа.

Гипотеза 3. Гипотеза ассиметрии информации: в случае, если акичи компаниипокупателя переоценены, вероятность использования акций в качестве средства платежа 
повыниается.

Данная гипотеза по-разному тестировалась в существующих эмпирических исследованиях. Согласно одному из мнений, для оценки переоцененности компании необходимо использовать долгосрочную избыточную доходность акций компаниипокупателя, однако, к сожалению, отсутствует консенсус по поводу того, каким образом необходимо считать данную доходность (Dong et al, 2006).

Вторым распространенным подходом является использование в качестве проксипеременной отношение рыночной стоимости собственного капитала к балансовой стоимости, Q Тобина и др. (Di Giuli, 2008). Данный подход является более распространенным, однако и у него имеются недостатки. Отношение рыночной стоимости собственного капитала к балансовой стоимости может значительно варьироваться для компаний, в зависимости от того, как часто происходит переоценка активов, по этой причине данное соотношение достаточно редко используется в практике оценки стоимости компаний, за исключением банков, которые обязаны очень точно отслеживать стоимость своих активов.

Более объективным показателем степени переоцененности акции компании-покупателя может являться изменение отношения рыночной стоимости собственного капитала к балансовой стоимости на протяжении какого-либо периода времени, например одного года. Данное соотношение показывает, насколько более «переоцененными» по отношению к балансовой стоимости стали акции компании за последний год. Годовой интервал является приемлемым, поскольку представляет собой временной горизонт, на который могут ориентироваться менеджеры компаний при оценке сроков рассмотрения, согласования и завершения сделок M\&A (Di Giuli, 2008).

Гипотеза 4. Гипотеза относительного размера: чем больше размер приобретаемой компании по сравнению с компанией-покупателем, тем выше вероятность использования акций в качестве способа оплатьл.

Для проверки данной гипотезы обычно используется отношение размера сделки к размеру приобретаемой компании (Martin, 1996). В качестве прокси для размера компании можно использовать различные метрики, однако наиболее целесообразно использовать, вопервых, метрики, основанные на рыночных данных, поскольку размер сделки является показателем не балансового типа; во-вторых, метрики, показывающие размер компании безотносительно к ее структуре капитала.

Наиболее подходящим показателем в данном случае является «стоимость компании» (enterprise value). Однако ввиду того что данный показатель достаточно сложен для расчета, он, скорее всего, будет недоступен для большинства компаний из развивающихся стран, поэтому в данном случае более целесообразным представляется использование показателя рыночной стоимости собственного капитала компании-цели. Данный подход был применен в работе Мартина (Martin, 1996). В качестве знаменателя можно использовать рыночную стоимость как компании-покупателя, так и объединенной компании.

Кроме относительно размера можно также рассмотреть влияние абсолютного размера сделки на использованный метод платежа. В данном случае целесообразно пользоваться логарифмом размера заключенной сделки $\mathrm{M} \& \mathrm{~A}$, поскольку значение имеет не сам размер сделки, а порядок значения.

Гипотеза 5. Гипотеза внешнего мониторинга: чем выше доля институциональных инвесторов в акционерном капитале компании-покупателя, тем выме вероятность использования денежных средств в качестве способа оплаты.

Для проверки данной гипотезы авторы используют три типа переменных, характеризующих степень внешнего контроля деятельности менеджеров компаниипокупателя: долю институциональных инвесторов, суммарный размер блокирующих пакетов (более 5\%), а также размер блокирующих пакетов, принадлежащих институциональным инвесторам (Martin, 1996).

Гипотеза 6. Гипотеза размера приобретаемой доли компании: чем больше размер приобретаемой доли, тем выше вероятность использования акций в качестве средства 
платежа.

Данная гипотеза не была освещена в предыдущих исследованиях.

Если компания приобретает значительную долю другой компании, то в попытке сохранить опытных менеджеров и членов совета директоров, а также вызвать их заинтересованность в успешной интеграции двух компаний менеджеры компаниипокупателя могут использовать акции в качестве средства платежа. Данный прием может являться альтернативой использования так называемых «выплат по результатам» (earn-out): в случае если в результате сделки M\&A будут достигнуты какие-либо заранее определенные финансовые результаты, акционеры и менеджеры приобретенной компании получат дополнительные выплаты. Данный эффект должен наблюдаться в случае приобретения значительной доли компании, однако будет незначительным в случае покупки сравнительно небольшого пакета акций.

Гипотеза 7. Гипотеза размера доли приобретаемой компании, которой владеет компания-покупатель на момент сделки: чем большей долей приобретаемой компании владеет компания-покупатель на момент заключения сделки, тем выше вероятность использования акиий в качестве средства платежа.

В случае если часть акционеров приобретаемой компании выступают против использования акций в качестве средства платежа, тот факт, что компания-покупатель уже владеет долей голосующих акций на момент согласования сделки, может упростить процесс принятия решения в пользу использования акций. Использование денежных средств может являться более предпочтительным для акционеров приобретаемой компании, поскольку в случае использования акций их цена в среднем падает после объявления о сделке, что негативно влияет на размер получаемых акционерами приобретаемой компании средств.

\section{Исследование детерминант метода платежа в сделках слияний и поглощений на развивающихся рынках БРИКС Характеристика выборки исследования}

Для проведения эмпирического исследования нами были выбраны четыре наиболее перспективные растущие рынки - Бразилия, Россия, Индия, Китай, Южная Африка, составляющие группу БРИКС. Данные страны представляют интерес, поскольку в последние два десятилетия в них наблюдался стремительный экономический рост, что отличает их от рассмотренных в предыдущих работах регионов, где темпы экономического роста значительно ниже. Кроме того, данные страны представляют в сумме более $60 \%$ общего объема сделок М\&A в развивающихся странах, что отчасти позволяет экстраполировать полученные выводы на развивающиеся рынки капитала в целом.

В качестве основного источника информации была использована база данных Блумберг (Bloomberg).

В первоначальную выборку вошли сделки слияний и поглощений, отвечающие следующим критериям:

- Официальные объявления о сделках M\&A были выпущены в период с 01.01.1999 по 01.01.2009. Данный временной отрезок был выбран потому, что на него приходится период быстрого роста экономик БРИКС. Кроме того, он полностью захватывает так называемую «шестую волну» сделок слияний и поглощений, согласно классификации Липтона (Lipton, 2006). Период 2009-2011 годов не был включен в выборку, поскольку для исследования необходимы данные о размере инвестиционных затрат компании-покупателя после завершения сделки. Данный выбор объясняется тем, что для завершения сделок зачастую требуется около года, а отчетность многих компаний за 2011 год на момент проведения исследования не была доступна.

- Компания-цель и компания-покупатель зарегистрированы в одной из стран БРИКС, и их основная деятельность приходится на развивающиеся рынки.

- Размер приобретаемой доли составляет не менее 5\%.

- Доля приобретаемой компании, которой владела компания-покупатель на момент 
объвления о сделке, не превышает 50\%.

- Размер сделки составляет не менее 1 млн долларов США. Данный критерий позволяет исключить заведомо малые сделки M\&A.

- Компании выборки не являются фирмами, оперирующими в финансовом секторе.

Количество сделок M\&A, подпадающих под данные критерии, составляет 2024. С учетом доступности финансовых данных, необходимых для проведения исследования (было показано выше), количество наблюдений в выборке сокращается до 825.

В таблице 2 представлено распределение сделок M\&A по методу платежа в исследуемых странах БРИКС.

Таблица 2

Распределение сделок М\&А по методу платежа в странах БРИКС

\begin{tabular}{|l|c|c|c|}
\hline & Денежные средства & Акции & Всего \\
\hline Количество сделок & 947 & 121 & 1,068 \\
\hline Количество сделок, \% & 88.67 & 11.33 & 100 \\
\hline Объем сделок, млрд долл. & 122,937 & 38,587 & 161,524 \\
\hline Объем сделок, \% & 76.11 & 23.89 & 100 \\
\hline
\end{tabular}

Источник: расчеты авторов

Как видно из таблицы 2, доминирующим методом платежа являются денежные средства, чья доля в количественном выражении составляет около 89\%. Однако в объемном выражении доля сделок, оплаченных с помощью денежных средств, составляет всего 76\%, что позволяет сделать вывод, что более крупные сделки, по-видимому, чаще оплачиваются с помощью акционерного капитала. Последний показатель незначительно отличается от среднемирового уровня, который в 2004-2012 годах составляет около $80 \%{ }^{19}$.

В таблице 3 представлено распределение сделок слияний и поглощений по странам.

Таблица 3

Распределение сделок М\&А по странам

\begin{tabular}{|l|c|c|c|c|}
\hline Страна & $\begin{array}{c}\text { Компания- } \\
\text { покупатель, } \\
\text { количество }\end{array}$ & $\begin{array}{c}\text { компания- } \\
\text { покупатель, \% }\end{array}$ & $\begin{array}{c}\text { Компания- } \\
\text { цель, } \\
\text { количество }\end{array}$ & $\begin{array}{c}\text { Компания- } \\
\text { цель, \% }\end{array}$ \\
\hline Бразилия & 64 & 7,76 & 67 & 8,12 \\
\hline Россия & 31 & 3,76 & 30 & 3,64 \\
\hline Индия & 137 & 16,61 & 132 & 16,00 \\
\hline Китай & 542 & 65,70 & 543 & 65,82 \\
\hline Юж. Африка & 51 & 6,18 & 53 & 6,42 \\
\hline
\end{tabular}

Источник: расчеты авторов

Согласно таблице 3, наибольшая доля сделок в численном выражении приходится на Китай и Индию, что объясняется размером их экономик в сравнении с другими странами БРИКС. Из рассматриваемой выборки 42 сделки $(5,1 \%)$ являются международными.

\section{Модель исследования и описание переменных}

В большинстве академических исследований, рассмотренных выше, основным методом эмпирической проверки выдвинутых гипотез является использование логистических регрессий. Исходя из гипотез, предложенных для тестирования на развивающихся рынках капитала, была сформулирована следующая регрессионная модель:

\footnotetext{
${ }^{19}$ Mergermarket M\&A Round Up 1Q2012.
} 
Payment $_{i}=\beta_{0}+\beta_{1} \operatorname{Re}$ lSize $_{i}+\beta_{2}$ PB $_{i}+\beta_{3}$ PBchange $_{i}+\beta_{4}$ AcqShare $_{i}+\beta_{5}$ OwnShare $_{i}+$

$+\beta_{6}$ InstOwn $_{i}+\beta_{7}$ CashToAssets $_{i}+\beta_{8}$ FcfToAssets $_{i}+\beta_{9}$ CapexToAssets $_{i}+\beta_{10}$ LogSize $_{i}+$

$+\beta_{11}$ RRatio $_{i}+\beta_{12}$ CRatio $_{i}$

В данной модели имеем бинарную зависимую переменную, которая принимает значения в зависимости от способа оплаты сделки: 0, если метод платежа - денежные средства, 1 - акции. Обозначения объясняющих переменных и способ их расчета представлены в приложении 1. В приложении 2 приведены основные характеристики рассматриваемых переменных, такие как среднее, минимальное, максимальное значения, стандартное отклонение.

\section{Эмпирические тесты и результаты}

В таблице 4 представлены результаты тестирования модели (1).

Таблица 4

Результаты тестирования логистической модели, выявляющей детерминанты метода платежа на выборке 825 сделок М\&А в странах БРИКС

\begin{tabular}{|c|c|c|c|c|c|c|}
\hline & \\
\hline & & & & & Кол-во набл, & 825 \\
\hline & & & & & LR chi2(12) & 223,66 \\
\hline & & & & & \begin{tabular}{|l|} 
Prob $>$ chi 2 \\
\end{tabular} & 0,0000 \\
\hline & & & & & Pseudo R2 & 0,3744 \\
\hline Payment & Коэфф, & Ст, откл, & $\mathrm{Z}$ & $\mathrm{P}>|\mathrm{z}|$ & \multicolumn{2}{|c|}{ [95\%Conf, Interval] } \\
\hline RelSize*** & 0,0385 & 0,0078 & 4,92 & 0,000 & 0,0231 & 0,0538 \\
\hline PB & 0,0027 & 0,0066 & 0,42 & 0,676 & $-0,0102$ & 0,0158 \\
\hline PBchange** & 0,0433 & 0,0192 & 2,25 & 0,024 & 0,0055 & 0,0811 \\
\hline AcqShare*** & 0,0441 & 0,0084 & 5,22 & 0,000 & 0,0275 & 0,0607 \\
\hline OwnShare*** & 0,0593 & 0,0145 & 4,09 & 0,000 & 0,0308 & 0,0877 \\
\hline InstOwn** & $-0,0125$ & 0,0058 & $-2,14$ & 0,033 & $-0,0240$ & $-0,0010$ \\
\hline CashToAssets*** & $-0,0557$ & 0,0167 & $-3,33$ & 0,001 & $-0,0884$ & $-0,0229$ \\
\hline FcfToAssets & $-0,0050$ & 0,0045 & $-1,12$ & 0,263 & $-0,0139$ & 0,0038 \\
\hline CapexToAssets** & $-0,2304$ & 0,0903 & $-2,55$ & 0,011 & $-0,4076$ & $-0,0533$ \\
\hline LogSize*** & 0,4316 & 0,0936 & 4,61 & 0,000 & 0,2480 & 0,6151 \\
\hline QRatio*** & $-0,7881$ & 0,2948 & $-2,67$ & 0,008 & $-1,3661$ & $-0,2102$ \\
\hline CRatio*** & $-0,9089$ & 0,2447 & 3,71 & 0,000 & 0,4292 & 1,3887 \\
\hline Константа*** & $-7,4335$ & 0,9299 & $-7,99$ & 0,000 & $-9,2561$ & $-5,6108$ \\
\hline \multicolumn{7}{|c|}{ *** результат значим на 1\%-ном уровне. } \\
\hline
\end{tabular}

Стоит отметить, что регрессия значима, значение псевдо-R2 составляет более $35 \%$, что является сравнительно хорошим показателем для финансовых рядов. На 10\%-ном уровне значимости незначимы всего два коэффициента (PB и FcfToAssets), хотя их знак совпадает с ожидаемым.

Исходная логистическая регрессия была проверена на мультиколлинеарность, в результате чего был сделан вывод, что имеет место мультиколлинеарность между переменными QRatio и CRatio. Для более корректной интерпретации знаков при коэффициентах переменная QRatio была исключена из логистической регрессии, после чего проблема мультиколлинеарности исчезла, значения VIF находятся в пределах 2 (Приложение 3). Таким образом, из модели в силу незначимости или мультиколлинеарности было исключено три коэффициента: PB, FcfToAssets и QRatio (Приложение 4). Стоит отметить, что исключение данных переменных практически никак не отразилось на значимости 
регрессии.

Для интерпретации результатов логистической регрессии нами использовались так называемые коэффициенты «отношения шансов» (Odds Ratio).

Полученные в ходе исследования результаты позволяют сделать следующие выводы относительно тестируемых гипотез:

- Гипотеза 1 (гипотеза доступности финансовых ресурсов) - гипотеза не отвергается на 1\%-ном уровне значимости. Значимый отрицательный коэффициент при переменной CashToAssets, позволяет утверждать, что чем больше у компании-покупателя имеется денежных средств и их эквивалентов, тем выше вероятность их использования в качестве средства платежа. Данный результат согласуется с результатами исследований развитых рынков (Martin, 1996; Zhang, 2001; Di Giuli, 2005). Коэффициент при второй переменной (CRatio) также значим, однако его знак отличается от ожидаемого, что позволяет заключить, что ликвидность компании, по-видимому, не является ограничением для использования денежных средств в качестве способа оплаты сделок. Знак коэффициента, вероятнее всего, объясняется отраслевой структурой, которая не была учтена в данном исследовании.

- Гипотеза 2 (гипотеза инвестиционных возможностей) - отвергается на 5\%-ном уровне значимости. Возможной причиной является то, что переменная, использованная для развитых рынков (размер фактических капитальных затрат после завершения сделки М\&A), является менее подходящей для использования на развивающихся рынках капитала.

- Гипотеза 3 (гипотеза ассиметрии информации) - гипотеза не отвергается на 5\%ном уровне значимости. Несмотря на то что коэффициент при переменной РВ оказался незначимым, его изменение за год, предшествующий объявлению о сделке, оказалось значимым и его знак совпал с ожидаемым. Данный вывод также хорошо согласуется с результатами исследований развитых стран (Dong et al., 2006; Rhodes-Kropf et al., 2005; Di Giuli, 2008).

- Гипотеза 4 (гипотеза относительного размера) - гипотеза не отвергается на 1\%ном уровне значимости. Значимый положительный коэффициент при переменной RelSize позволяет утверждать, что в странах БРИКС относительный размер покупаемой компании является важной детерминантой метода платежа, как и абсолютный размер сделки. Данный результат совпадает с полученным в работе Груллона и др., и Ди Гиули, однако противоречит выводам, полученным в работе Мартина (Grullon, 1997; Di Giuli, 2008; Martin, 1996).

- Гипотеза 5 (гипотеза внешнего мониторинга) - гипотеза не отвергается на 1\%ном уровне значимости. Это позволяет утверждать, что чем большей долей компаниипокупателя владеют институциональные инвесторы, тем более затруднительно использование акций в качестве средства платежа.

- Гипотезы 6 и 7 (гипотезы приобретаемой доли и доли, которой компанияпокупатель владела на момент сделки) - гипотезы не отвергаются на 1\%-ном уровне значимости. Данные гипотезы не отвергаются, поскольку коэффициенты при соответствующих переменных значимы и знаки совпадают с ожидаемыми.

Гипотеза о влиянии структуры собственности на выбор метода платежа не была предложена к тестированию в данной работе ввиду отсутствия необходимой информации о доле менеджмента в акционерном капитале компаний.

Результаты проведенного исследования позволяют заключить, что большинство детерминант метода платежа в сделках слияний и поглощений, которые значимы в развитых странах, также значимы и в развивающихся. Кроме того, были выдвинуты и подтверждены новые гипотезы относительно детерминант метода платежа в сделках M\&A (гипотезы приобретаемой доли и доли, которой компания-покупатель владела на момент сделки). 


\section{Заключение}

В результате эмпирического исследования детерминант метода платежа в сделках M\&A на выборке 825 сделок в странах БРИКС в период с 1999 по 2009 год было выявлено, что основными факторами, объясняющими выбор способа оплаты слияний и поглощений, являются: доступность финансовых ресурсов, относительный и абсолютный размер сделки, динамика отношения рыночной стоимости компании-покупателя к балансовой стоимости. Кроме того, важную роль также играют доля институциональных инвесторов в акционерном капитале компании-покупателя, размер приобретаемой доли компании, а также доля приобретаемой компании, которой компания-покупатель владела на момент сделки. Сопоставление полученных выводов с результатами исследований развитых стран показало, что большинство факторов, влияющих на выбор метода платежа в развитых странах, также значимы и на развивающихся рынках капитала. Выявленные детерминанты помогут менеджерам компаний в принятии решений, относящихся к выбору метода платежа в сделках слияний и поглощений.

Основным ограничением данного исследования является тот факт, что значительное число сделок было исключено из рассмотрения ввиду отсутствия необходимой информации. Среди направлений дальнейших исследований можно выделить следующие: рассмотрение воздействия инвестиционных возможностей компании-покупателя и поиск подходящих для этого прокси-переменных, уточнение влияния ликвидности на метод платежа с учетом отраслевой специфики, дальнейшее тестирование гипотезы размера имеющейся и приобретаемой долей компании-цели.

\section{Список литературы}

1. Аглиарди Э., Лукьянова И. Финансовый рычаг, доходность и отраслевая специфика: эмпирическое исследование сделок слияний и поглощений // Корпоративные финансы. 2011. № 4.4 C. $44-76 . \quad$ URL: http://cfjournal.hse.ru/data/2012/02/02/1262787487/CFJ20_54_76_Agliardi_Lukianova_.pd f.

2. Amihud, Y., Lev, B., Travlos, N. (1990), Corporate control and the choice of investment financing: the case of corporate acquisition. Journal of Finance, 45 (1990) 603-616

3. Asquith, P., Bruner, R., Mullins, D. (1990), Merger returns and the form of financing, Massachusetts Institute of Technology (MIT), Working paper.

4. Blackburn, V., Dark F., Hanson, R. (1997), Mergers, method of payment and returns to manager- and owner- control firms, The Financial Review, 32(3) (1997) 569-589.

5. Bruner, R.F. (2004), Where M\&A Pays and Where It Strays: A Survey of the Research, Journal of Applied Corporate Finance, 16 (2004) 63-76.

6. Cornett, M., De, S. (1991), Medium of payment in corporate acquisitions: evidence from interstate bank mergers, Journal of Money, Credit and Banking, 23 (1991) 767-776.

7. Di Giuli, A. (2007), Cash or stock? The Post Merger Investments as the Key to explain the Method of Payment in Mergers, Bocconi University, Working Paper.

8. Dong, M. Hirshleifer, D., Richardson, S., Hong Teoh, S. (2006), Does investor misvaluation drive the takeover market?, Journal of Finance, 61 (2006) 725-762.

9. Faccio, M., Masulis, R.W. (2004), The choice of payment method in European mergers and acquisitions, The Journal of Finance, 60 (2004) 1345-1388.

10. Ghosh, A., Ruland, W. (1998), Managerial ownership, the method of payment for acquisitions, and executive job retention, Journal of Finance, 53 (1998) 785-798.

11. Grinblatt, M., Titman, S. (2002), Financial Markets and Corporate Policy. McGraw-Hill., Ch.20, p. 691-729.

12. Grullon, G., Michaely, R., Swary, I. (1997), Capital adequacy, bank mergers, and the 
medium of payment, Journal of Business Finance and Accounting, 24(1) (1997) 97-124.

13. Hansen, R. (1987), A theory for the choice of exchange medium in mergers and acquisitions, Journal of Business, 60 (1987) 75-95.

14. Lamont, O. (2000), Investment plans and stock returns, Journal of Finance, 55(6) (2000) 2719-2745.

15. Lipton, M. (2006), Merger Waves in the 19th, 20th and 21st Centuries, Working Paper, York University.

16. Martin, K. (1996), The method of payment in corporate acquisitions, investment opportunities, and management ownership, Journal of Finance, 4 (1996) 1227-1246.

17. Martynova, M., Renneboog, L. (2011). Sources of financing and means of payment in M\&As, in: Baker H.K., Kiymaz H. (eds.). The art of capital restructuring. Creating shareholder value through mergers and acquisitions. John Wiley \& Sons, Inc., Ch. 12, p. 205-221.

18. Martynova, M., Renneboog, L. (2009), What determines the financing decision in corporate takeovers: cost of capital, agency problems, or the means of payment?, Journal of Corporate Finance, 15(3) (2009) 290-315.

19. Myers, S.C. (1977), Determinants of corporate borrowing, Journal of Financial Economics, 5 (1977) 147-175.

20. Myers, S., Majluf, N. (1984), Corporate financing and investment decisions when firms have information that investors do not have, Journal of Financial Economics, 13 (1984) $187-221$.

21. Rhodes-Kropf, M., Robinson, D.T., Viswanathan S. (2005), Valuation waves and merger activity: The empirical evidence, Journal of Financial Economics, 77(3) (2005) 561-603.

22. Song, M., Walkling, R. (1993), The impact of managerial ownership on acquisition attempts and target shareholder wealth, Journal of Financial and Quantitative Analysis, 28(4) (1993) 439-457.

23. Stulz, R. (1988), Managerial control of voting rights - financing policies and the market for corporate control, Journal of Financial Economics, 20 (1988) 25-54.

24. Travlos, N. (1987), Corporate takeover bids, methods of payment, and bidding firms' stock returns, Journal of Finance, 42 (1987) 943-963.

25. Zhang, Ping-shun (2001), What really determine the payment methods in M\&A Deals, Manchester School of Management, Working Paper No. 0103. 


\section{Приложения}

Приложение 1

Обозначения объясняющих переменных и способ их расчета в модели исследования детерминант метода платежа в странах БРИКС

\begin{tabular}{|c|c|}
\hline Переменная & Описание переменной \\
\hline RelSize & $\begin{array}{l}\text { Относительный размер сделки. Отношение объема сделки М\&А в } \\
\text { долларах США к рыночной капитализации компании-покупателя, среднее } \\
\text { значение за } 30 \text { дней предшествующих официальному объявлению о сделке }\end{array}$ \\
\hline$P B$ & $\begin{array}{l}\text { Отношение рыночной капитализации компании-покупателя к } \\
\text { балансовой стоимости собственного капитала компании-покупателя. } \\
\text { Среднее значение за } 30 \text { дней, предшествующих дате официального } \\
\text { объявления о сделке }\end{array}$ \\
\hline PBchange & $\begin{array}{l}\text { Изменение отношения рыночной капитализации компании-покупателя } \\
\text { к балансовой стоимости собственного капитала. Процентное изменение } \\
\text { среднего показателя отношения рыночной стоимости компании-покупателя } \\
\text { к балансовой стоимости компании-покупателя за } 30 \text { дней, предшествующих } \\
\text { официальному объявлению о предстоящей сделке, к среднему значению } \\
\text { показателя за аналогичный период предшествующего года } \\
\end{array}$ \\
\hline AcqShare & $\begin{array}{l}\text { Приобретаемая доля (в процентах), в результате сделки слияния и } \\
\text { поглощения }\end{array}$ \\
\hline OwnShare & $\begin{array}{l}\text { Изначальная доля владения (в процентах). Доля компании-покупателя, } \\
\text { которой она владела на момент совершения сделки }\end{array}$ \\
\hline InstOwn & $\begin{array}{l}\text { Доля компании-покупателя, которой владеют институциональные } \\
\text { акционеры. По состоянию на дату объявления о сделке }\end{array}$ \\
\hline CashToAssets & $\begin{array}{l}\text { Отношение денежных средств и высоколиквидных финансовых } \\
\text { активов к балансовой стоимости активов компании. Отношение } \\
\text { величины денежных средств и их эквивалентов к балансовой стоимости } \\
\text { активов компании в среднем за год, предшествующий официальному } \\
\text { объявлению о сделке }\end{array}$ \\
\hline FcfToAssets & $\begin{array}{l}\text { Отношение свободного денежного потока к балансовой стоимости } \\
\text { активов компании. Отношение свободного денежного потока за год, } \\
\text { предшествующй официальному объявлению о предстоящей сделке, к } \\
\text { средней балансовой стоимости активов компании }\end{array}$ \\
\hline CapexToAssets & $\begin{array}{l}\text { Отношение капитальных затрат к стоимости активов. Отношение } \\
\text { общего объема капитальных затрат компании за год, следующий за датой } \\
\text { завершения сделки, к средней балансовой стоимости активов за } \\
\text { аналогичный период }\end{array}$ \\
\hline LogSize & $\begin{array}{l}\text { Логарифм размера сделки. Данная переменная представляет собой } \\
\text { натуральный логарифм от размера сделки в миллионах долларах США }\end{array}$ \\
\hline QRatio & $\begin{array}{l}\text { Коэффициент быстрой ликвидности = (денежные средства и их } \\
\text { эквиваленты }+ \text { краткосрочные ликвидные ценные бумаги }+ \text { кредиторская } \\
\text { задолженность)/текущие обязательства }\end{array}$ \\
\hline CRatio & $\begin{array}{l}\text { Коэффициент текущей ликвидности }=\text { текущие } \text { активы/текущие } \\
\text { обязательства }\end{array}$ \\
\hline
\end{tabular}


Описательные статистики переменных

Приложение 2

\begin{tabular}{|l|c|c|c|c|}
\hline Переменная & Среднее & Ст. откл. & Мин. & Макс \\
\hline RelSize, \% & 8,1 & 19,7 & 0,003 & 156,2 \\
\hline PB & 5,0 & 19,2 & 0,01 & 537,6 \\
\hline PBchange, \% & $-0,46$ & 6,71 & -66 & 54 \\
\hline AcqShare, \% & 73,5 & 29,2 & 5,97 & 100 \\
\hline OwnShare, \% & 6,0 & 13,2 & 0 & 49,5 \\
\hline InstOwn,\% & 32,7 & 27,2 & 0 & 99,4 \\
\hline CashToAssets, \% & 12,9 & 11,9 & 0,03 & 97,9 \\
\hline FcfToAssets, \% & $-0,87$ & 43,4 & $-64,8$ & 97,7 \\
\hline CapexToAssets, \% & 1,41 & 2,4 & 0,00 & 24,6 \\
\hline LogSize & 2,7 & 1,65 & 0,01 & 9,5 \\
\hline QRatio,\% & 1,26 & 1,94 & 0 & 31,5 \\
\hline CRatio, \% & 1,93 & 2,10 & 0,13 & 34,2 \\
\hline
\end{tabular}

Источник: расчеты авторов

Приложение 3

Проверка переменных модели (1) на мультиколлинеарность

\begin{tabular}{|r|rr|}
\hline Variable & VIF & $1 /$ VIF \\
\hline AcqShare & 1.64 & 0.609819 \\
OwnShare & 1.61 & 0.622190 \\
LogSize & 1.36 & 0.735191 \\
Re1Size & 1.27 & 0.788152 \\
CashToAssets & 1.17 & 0.852923 \\
currentratio & 1.16 & 0.860133 \\
InstOwn & 1.12 & 0.889093 \\
CapexToAss s & 1.07 & 0.932088 \\
PBchange & 1.01 & 0.988373 \\
\hline Mean VIF & 1.27 & \\
\hline
\end{tabular}

Источник: расчеты авторов

Приложение 4

Результаты тестирования логистической модели, выявляющей детерминанты метода платежа на выборке 825 сделок M\&A в странах БРИКС, после исключения переменных РВ,

FcfToAssets и QRatio

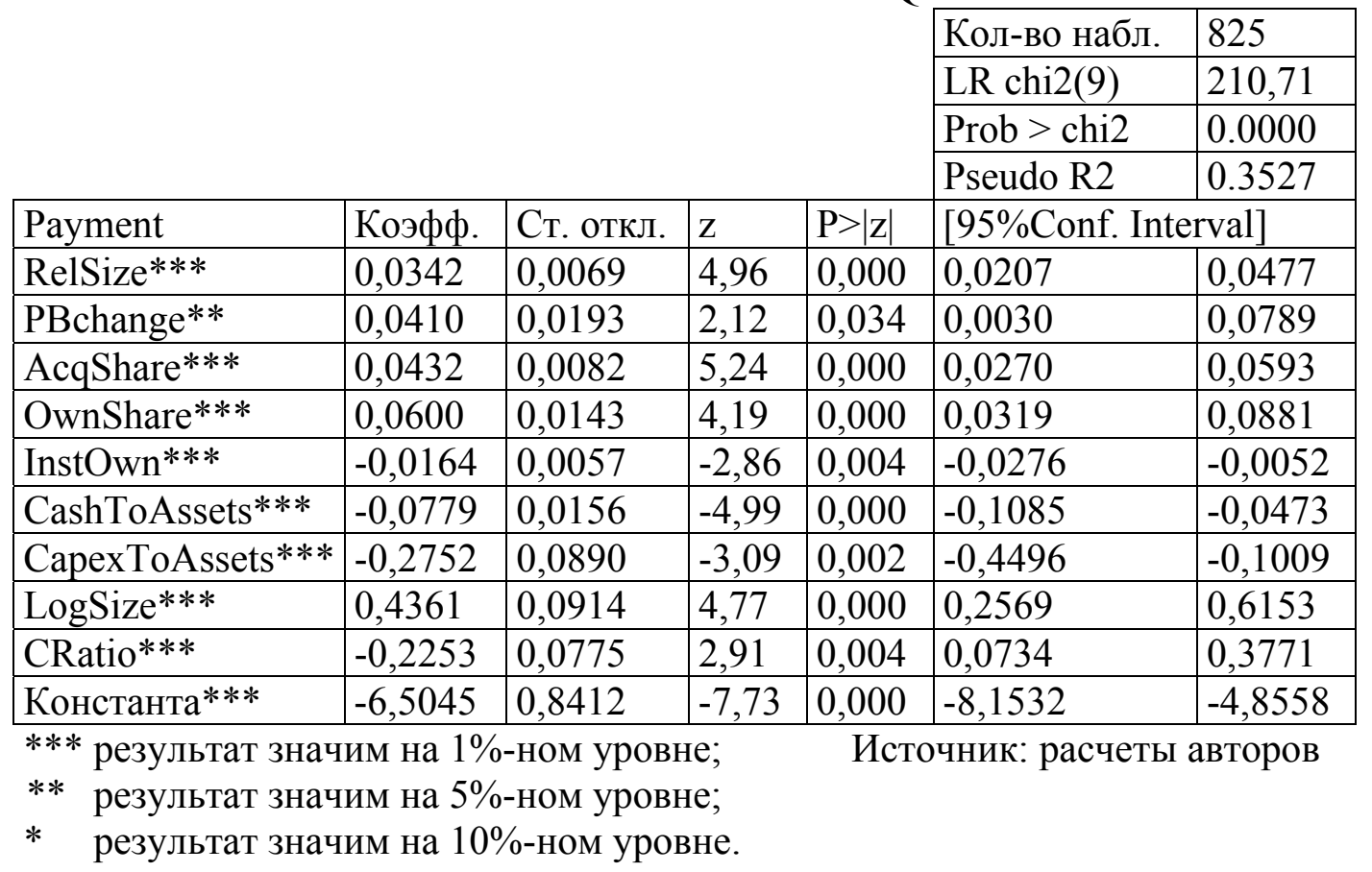

